\title{
Molecular weight, tertiary structure, water binding and colon behaviour of ispaghula husk fibre
}

\author{
Saphwan Al-Assaf ${ }^{1}$, Glyn O. Phillips ${ }^{1 *}$, Peter A. Williams ${ }^{1}$, Shoji Takigami², \\ Peter Dettmar ${ }^{2}$ and Michael Havler ${ }^{3}$ \\ ${ }^{1}$ The North East Wales Institute, Plas Coch, Mold Road, Wrexham LL1 2AW, UK \\ ${ }^{2}$ University of Gunma, Kiryu, Gunma-ken, Japan \\ ${ }^{3}$ Reckitt Benckiser plc, Dansom Lane, Kingston upon Hull HU8 7DS, UK
}

\begin{abstract}
Molecular variables, using aqueous and alkaline extracts, of the polysaccharide from ispaghula husk (IH) were examined using gel-permeation chromatography linked to multi-angle laser light scattering. Progressive extraction can yield a component with a molecular weight (MW) value up to about $7 \times 10^{6} \mathrm{Da}$, and gels, which accompany the extraction, have MW ranging from $10-20 \times 10^{6} \mathrm{Da}$. To mimic the polysaccharide degradation, particularly in the colon, the solid $\mathrm{IH}$ was degraded progressively using ionising radiation. A chain break occurs every $7 \cdot 5 \mathrm{kGy}$ in $\mathrm{NaOH}$ and every $15 \mathrm{kGy}$ in water. The solid-state matrix is opened by the radiation to yield increased visco-elasticity of the aqueous extracts at critical radiation doses, before further degradation occurs after about $12 \mathrm{kGy}$. Differential scanning calorimetry is used to study the mechanism of interaction of water with IH. The first water to be taken up is non-freezing water and represents about twelve water molecules/disaccharide unit of the polysaccharide. As the water content is increased, the water becomes bound to the polysaccharide and freezes and melts at a temperature different from free water. This water is thermodynamically distinguishable from free water. It forms amorphous ice on cooling which crystallises exothermically and subsequently melts endothermically. Saturation occurs at a water content of $2-3 \mathrm{~g}$ water/g polymer, showing that about $60 \%$ of the water in the system is 'bound'. The most surprising conclusion is that despite the fact that the IH swells in water to form a solid and stiff gel, the greater part of that water in the gel is still free and behaves like liquid water.
\end{abstract}

Non-starch polysaccharides: Ispaghula husk: Colon: Gel permeation chromatography: Multi-angle laser light scattering

Plantago ovata or P. espaghua (Plantaginaceae) is native to the Canary Islands and the Mediterranean regions of Southern Europe and is also indigenous to the Indo-Pak subcontinent. Its seed husk (ispaghula) is a rich source of effective polysaccharide (dietary) fibre for promoting the healthy functioning of the colon (Marteau et al. 1994). A factor in its physiological fibre behaviour is its high viscosity and gel-like character in water. This property, in turn, is related to the molecular variables associated with this extremely high-molecular-weight polysaccharide.

In the present study the molecular variables associated with the polysaccharide were first investigated. The behaviour of the polysaccharide in water is unusual. Immediately (within $1 \mathrm{~min}$ ) it is suspended in water fine whiskers grow out of the solid. This behaviour continues and the fibres grow with time until the solid has been converted, first into a soft gel and then into a stiff gel. It is this interaction with water that controls the rheological behaviour of this polysaccharide, which in turn is partly responsible for its effectiveness in increasing stool bulk and decreasing stool transit time. There are, however, in vivo changes and modifications that occur after exposure to the fermentation activity of the colonic microflora. To mimic this behaviour controlled degradation studies were carried out and the effects on rheological performance studied. The objective was to follow the breakdown of the tertiary matrix via the gel into the water-soluble state and evaluate how this progression might relate to its functionality within the colon and lead to the various physiological benefits that have been reported. 


\section{Measurements of molecular and rheological variables}

The ispaghula husk (IH) samples used for the present study were provided by Reckitt Benckiser plc (Kingston upon Hull, East Yorkshire, UK). Its weight-average molecular weight (MW) was measured using a gel-permeation chromatography column linked to the DAWN-DSP multi-angle laser light-scattering photometer, with a K5 flow cell (Wyatt Technology Corporation, Santa Barbara, CA, USA) along with the associated software and Wyatt/Optilab DSP interferometer refractometer. Details have been reported previously (Milas et al. 2001). For these measurements our determined value of $0 \cdot 116$ was used for the refractive index increment (dn/dc).

For high-MW materials this technique is inadequate and flow-field-flow fractionation (FFF) was used. FFF is a flexible elution technique capable of simultaneous separation of particles and macromolecules according to their size. Here the separation takes place in a thin open channel through which the sample is transported by a laminar flow of liquid. The action of a field (cross-flow) applied perpendicularly to the channel flow causes a partitioning of the various components into regions of different flow velocities depending on their diffusion coefficient. It has been shown recently that flow-FFF is an effective technique for the determination of the MW distribution of polymers such as glutenin (Wahlund et al. 1996), amphiphilic graft copolymers (Wittgren et al. 1996), carrageenan and xanthan (Viebke \& Williams, 2000). Full details of the uses of the FFF equipment are given elsewhere (Al-Assaf et al. 2002).

Fig. 1 gives the light scattering and refractive index response for a typical sample. The former gives the distribution of MW within the polydisperse material and the latter the mass distribution. The traces do not coincide as a smaller amount of high-MW-material makes a greater contribution to the light-scattering trace. A weight-average MW for two repeat runs was $1.25 \times 10^{6}$ and $1.21 \times 10^{6} \mathrm{Da}$, indicating good reproducibility. The $\mathrm{MW}$ of the fractions within the sample ranges from about $200 \mathrm{kDa}$ to $4 \times 10^{6} \mathrm{Da}$. Heating for 15 and $60 \mathrm{~min}$ at $90^{\circ} \mathrm{C}$ reduces the weight-average MW by approximately $25 \%$. Different samples, each of which was polydisperse, had weight-average MW ranging from 1.25 to $1.67 \times 10^{6} \mathrm{Da}$. In water, using a mobile phase of $0 \cdot 1 \mathrm{M}-\mathrm{NaOH}$, a somewhat higher weight-average MW was

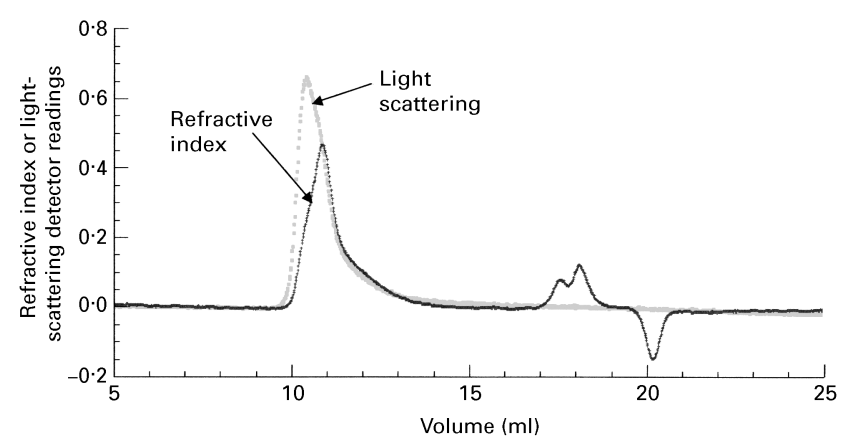

Fig. 1. Gel-permeation chromatogram showing the elution profiles monitored by light scattering and refractive index for ispaghula husk dissolved in $0.1 \mathrm{M}-\mathrm{NaOH}$. Mobile phase was $0.1 \mathrm{M}-\mathrm{NaOH}$. (.....), refractive index detector (indicates mass distribution); (•...•), light-scattering detector (indicates molecular weight distribution). found, varying from 1.65 to $1.89 \times 10^{6} \mathrm{Da}$, indicating that some degradation of IH occurs with heat and with $0 \cdot 1 \mathrm{M}-\mathrm{NaOH}$. Prolonged hydration leads to a further increase in the MW of the extracted material from solid matrix. Two distinct components can be observed. Each component can be processed separately, and the higher component has an average MW of approximately $7 \times 10^{6}$ Da. The results for the same sample subjected to different treatments are summarised in Table 1.

Thus, it is evident that the tertiary structure of $\mathrm{IH}$ supports a very high-MW polysaccharide associated with a small amount of protein. A polysaccharide with a MW up to about $6 \times 10^{6} \mathrm{Da}$ can be extracted with water until eventually gelation occurs. In $0 \cdot 1 \mathrm{M}-\mathrm{NaOH}$ it is possible that some degradation occurs.

\section{Degradation by ionising radiation}

IH was irradiated in the solid state with progressively increasing doses of ${ }^{137} \mathrm{Cs} \gamma$-radiation from 2 to $22 \mathrm{kGy}$. The weight-average MW for the soluble fraction when the irradiated solid was dissolved in $0.1 \mathrm{M}-\mathrm{NaOH}$ are given in Table 2 and the corresponding values when the soluble

Table 1. Molecular weight variables for ispaghula husk in different conditions*

\begin{tabular}{|c|c|c|c|}
\hline \multirow[b]{2}{*}{ Sample } & \multicolumn{2}{|c|}{$\begin{array}{l}\text { Molecular weight } \\
\qquad\left(\times 10^{6} \mathrm{Da}\right)\end{array}$} & \multirow[b]{2}{*}{ Comments } \\
\hline & Mean & Range & \\
\hline \multirow[t]{3}{*}{1} & $6 \cdot 82$ & $7 \cdot 01-6 \cdot 63$ & $\begin{array}{l}\text { In water ( } 3 \mathrm{~d} \text { hydration); mobile } \\
\text { phase: water }\end{array}$ \\
\hline & $3 \cdot 10$ & $3 \cdot 34-2 \cdot 86$ & Processed as two peaks \\
\hline & $6 \cdot 33$ & $6 \cdot 53-6 \cdot 13$ & Processed as one peak \\
\hline \multirow[t]{3}{*}{2} & $7 \cdot 20$ & $7 \cdot 46-6 \cdot 94$ & $\begin{array}{l}\text { In water ( } 20 \mathrm{~d} \text { hydration); mobile } \\
\text { phase: water }\end{array}$ \\
\hline & $4 \cdot 29$ & $4 \cdot 62-3 \cdot 96$ & Processed as two peaks \\
\hline & $6 \cdot 63$ & $6 \cdot 90-6 \cdot 36$ & Processed as one peak \\
\hline 3 & $1 \cdot 62$ & $1 \cdot 67-1 \cdot 57$ & $\begin{array}{l}\text { In } 0.1 \mathrm{M}-\mathrm{NaOH} ; \text { mobile phase: } \\
0.1 \mathrm{M}-\mathrm{NaOH}\end{array}$ \\
\hline 4 & $2 \cdot 36$ & $2 \cdot 42-2 \cdot 30$ & $\begin{array}{l}\text { In water ( } 3 \mathrm{~d} \text { hydration); mobile } \\
\text { phase: } 0 \cdot 1 \mathrm{M}-\mathrm{NaOH}\end{array}$ \\
\hline
\end{tabular}

*For details of procedures, see p. 212.

Table 2. Ispaghula husk irradiated in the solid state and the soluble component (dissolved in $0 \cdot 1 \mathrm{M}-\mathrm{NaOH}$ ) measured by gel-permeation chromatography-multi-angle laser light scattering*

\begin{tabular}{lcl}
\hline $\begin{array}{l}\text { Molecular weight } \\
\left(\times 10^{6} \mathrm{Da}\right)\end{array}$ & pd & Comments \\
\hline 1.62 & 1.45 & Control \\
1.62 & 1.40 & Control, repeated run \\
1.54 & 1.42 & Irradiated at $2 \mathrm{kGy}$ \\
1.25 & 1.82 & Irradiated at $4 \mathrm{kGy}$ \\
1.18 & 2.00 & Irradiated at $6 \mathrm{kGy}$ \\
1.12 & 2.01 & Irradiated at $8 \mathrm{kGy}$ \\
0.95 & 2.22 & Irradiated at $14 \mathrm{kGy}$ \\
0.73 & 2.00 & Irradiated at $22 \mathrm{kGy}$ \\
\hline
\end{tabular}

pd, polydispersity.

*Ispanghula husk was dissolved in $0.1 \mathrm{M}-\mathrm{NaOH}$. Mobile phase was $0.1 \mathrm{M}$ $\mathrm{NaOH}$, flow rate was $1 \mathrm{ml} / \mathrm{min}$, injected volume was $250 \mu \mathrm{l}$ soluble fraction $(2 \%, w / v)$. 
Table 3. Ispaghula husk irradiated in the solid state and the soluble component (dissolved in water) measured by gel-permeation chromatography multi-angle laser light scattering*

\begin{tabular}{lll}
\hline $\begin{array}{l}\text { Molecular weight } \\
\left(\times 10^{6} \mathrm{Da}\right)\end{array}$ & pd & Comments \\
\hline 2.36 & 1.57 & Control \\
1.77 & 2.04 & Irradiated at $2 \mathrm{kGy}$ \\
1.57 & 2.06 & Irradiated at $4 \mathrm{kGy}$ \\
1.35 & 2.06 & Irradiated at $6 \mathrm{kGy}$ \\
1.01 & 2.12 & Irradiated at $8 \mathrm{kGy}$ \\
0.81 & 2.11 & Irradiated at $14 \mathrm{kGy}$ \\
\hline
\end{tabular}

pd, polydispersity.

*Ispaghula husk was dissolved in water. Mobile phase was $0 \cdot 1 \mathrm{M}-\mathrm{NaOH}$, flow rate was $1 \mathrm{ml} / \mathrm{min}$, injected volume was $50 \mu \mathrm{l}$ soluble fraction $(2 \%, \mathrm{v} / \mathrm{v})$.

fraction is dissolved in water are given in Table 3. The degradation was pronounced in both systems.

There was a regular decrease in MW and the polydispersity increased, with the differential root mean square radius $\left(\mathrm{R}_{\mathrm{g}}\right)$ changing from having a $50 \%$ weight fraction of root mean square radius of about $50 \mathrm{~nm}$ to a value of about $20 \%$ weight fraction having a mean $\mathrm{R}_{\mathrm{g}}$ of about $35 \mathrm{~nm}$, with a distribution spanning the entire range. From the linear relationship of chain breaks per molecule with dose, it can be calculated that one break occurs in solid IH for every $7 \cdot 5 \mathrm{kGy}$ in $\mathrm{NaOH}$ and every $15 \mathrm{kGy}$ in water. It is evident that the labile groups, which are introduced by radiation, are twice as susceptible to breakdown in $\mathrm{NaOH}$ as in water. Thus, using this relationship it is possible to calculate the extent of degradation at any given dose.

\section{Field-flow fractionation combined with multi-angle laser light scattering}

For FFF examination IH samples were prepared by dissolving $0.2 \mathrm{~g} \mathrm{IH}$ in $20 \mathrm{ml}$ water. The fraction after water equilibration was filtered through a $1.0 \mu \mathrm{m}$ filter and $50 \mu \mathrm{l}$ was injected into the FFF channel. Following injection the sample was left to relax to its equilibrium distribution (separation of molecules according to their diffusion coefficient) under the influence of the cross-flow and channel flow. At this stage there was no channel flow leaving the channel outlet. After this relaxation time a crossflow of $0.5-3.0 \mathrm{ml} / \mathrm{min}$ is maintained and a channel flow rate of $0.25 \mathrm{ml} / \mathrm{min}$ was used to elute the sample. Since the diffusion coefficient directly governs the retention time it was necessary to perform the separation under constant temperature. Thus, all measurements were carried out at $40^{\circ} \mathrm{C}$.

A range of IH (unirradiated and irradiated) samples were examined using this technique. The weight-average MW can be calculated using a first-order fit and a second-order fit. This procedure is necessary since the scattering function gives a linear graph for small molecules but is curved for larger molecules or particles. The soluble fraction in water was used to avoid alkaline degradation in $0 \cdot 1 \mathrm{M}-\mathrm{NaOH}$. Using the first-order fit, the weight-average MW for the unirradiated $\mathrm{IH}$ was about $10 \times 10^{6} \mathrm{Da}$, falling to about $7 \times 10^{6} \mathrm{Da}$ on irradiation. The error in this determination was about $20 \%$ due to the large molecules (particles). Thus,

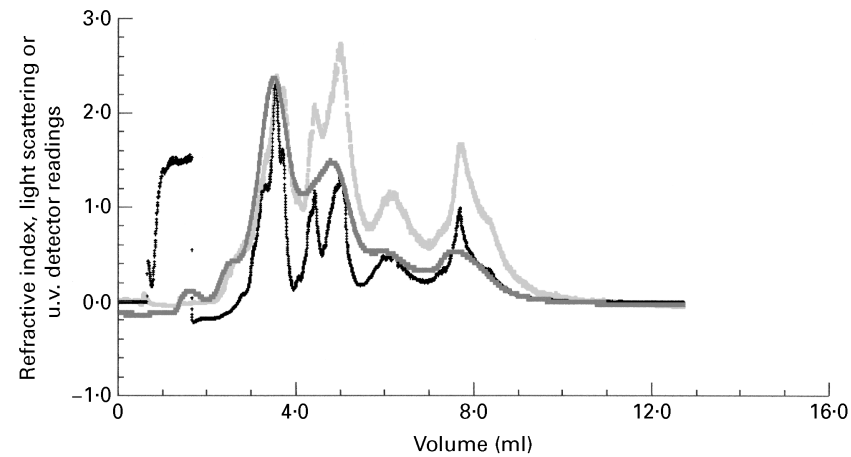

Fig. 2. Molecular-weight distribution of ispaghula husk using fieldflow fractionation. Ispaghula husk was dissolved in water. The mobile phase was water. (....), refractive index detector (indicates mass distribution); (•••), , light scattering detector (indicates molecular weight distribution); ( $\cdots \cdots)$, u.v. detector (indicates protein distribution).

it was necessary to use different orders of fit to improve the accuracy of extrapolation. On using second-order fit the weight-average $\mathrm{MW}$ for the unirradiated sample was about $20 \times 10^{6} \mathrm{Da}$ and about $15 \times 10^{6} \mathrm{Da}$ for the irradiated sample, with a reasonable experimental error of about $10 \%$.

Fig. 2 shows the MW distribution of IH using FFF from which the distribution of components can be shown. There are separate traces for the distribution of components of varying size. The distribution of MW can be seen from the light-scattering detector, the mass distribution from the refractive index detector and the protein distribution from the u.v. detector at $214 \mathrm{~nm}$. It would appear that the protein is associated with each MW component equally. From a study of several samples it can be concluded that the weightaverage value of MW for the IH is about $20 \times 10^{6} \mathrm{Da}$ for the unirradiated $\mathrm{IH}$ and about $15 \times 10^{6} \mathrm{Da}$ after irradiation to $8 \mathrm{kGy}$. Thus using FFF, the particles that do not elute within the gel-permeation chromatography columns can be evaluated.

\section{Rheological measurements}

Oscillation measurements for the alkaline extract showed that at low frequency the storage modulus $\left(\mathrm{G}^{\prime}\right)$ and loss modulus $\left(\mathrm{G}^{\prime \prime}\right)$ almost overlap for the control unirradiated IH matrix. As IH is degraded there is first a decrease in $\mathrm{G}^{\prime}$ and an increase in $\mathrm{G}^{\prime \prime}$. Thus, in its original state the IH behaves as a gel-like visco-elastic matrix, but as it is progressively degraded to about $40 \%$ of its original MW it observes only viscous solution behaviour. Gel-like behaviour was observed when the bulk properties of $\mathrm{IH}$ were examined (i.e. containing the soluble and insoluble fraction). Due to the heterogeneous nature of the system when IH hydrates, aggregation of individual chains can also occur. For this reason it was necessary to gently homogenise the suspension before measurements. Thereafter, $\mathrm{G}^{\prime}$ is greater than $G^{\prime \prime}$ over the entire range of frequency and with good reproducibility. The same behaviour is observed for IH in water, $\mathrm{NaCl}$ or in acidic conditions $(\mathrm{pH} 2)$. On irradiation the bulk rheology showed an increase in $\mathrm{G}^{\prime}$ and $\mathrm{G}^{\prime \prime}$ at certain radiation dose ranges (Fig. 3). At specific molecular dimensions there is an opening up of the three-dimensional matrix. 


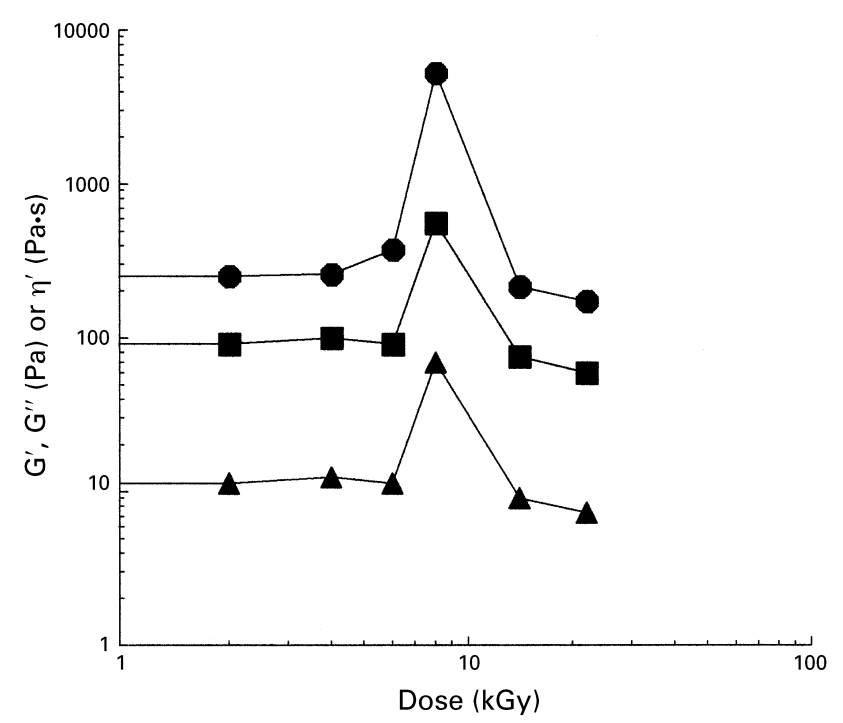

Fig. 3. Effect of ${ }^{60} \mathrm{Co} \gamma$-radiation on storage modulus (G'; --0-), loss modulus ( $\left.G^{\prime \prime} ;-\mathbf{-}-\right)$ and dynamic viscosity $\left(\eta^{\prime} ;-\mathbf{\Delta}-\right)$ of ispaghula husk.

This leads to pronounced visco-elasticity reflected by the transition to a strong gel behaviour when $\mathrm{G}^{\prime}$ and $\mathrm{G}^{\prime \prime}$ are independent of frequency. It was found that it is the transparent gel fraction that is mainly responsible for this increase, and it is our view that gel domains within the matrix are responsible for this behaviour.

\section{Interaction of ispaghula husk with water}

Differential scanning calorimetry was used to establish how the water interacts with the polysaccharide associated with the IH at the molecular level. Full details of the methods have been previously described (Takigami et al. 1995). Water content $\left(\mathrm{W}_{\mathrm{c}}\right)$ is defined as:

$$
\mathrm{W}_{\mathrm{c}}(\mathrm{g} / \mathrm{g})=\frac{\text { weight of water }(\mathrm{g}) \text { in polysaccharide }}{\text { weight of dry polysaccharide }(\mathrm{g})} \text {. }
$$

It is possible to distinguish between non-freezing water $\left(\mathrm{W}_{\mathrm{nf}}\right)$, freezing-bound water $\left(\mathrm{W}_{\mathrm{fb}}\right)$ and free water $\left(\mathrm{W}_{\mathrm{f}}\right)$ from the individual transitions or shape of the transitions, and these variables are connected by the relationship:

$$
\mathrm{W}_{\mathrm{c}}=\mathrm{W}_{\mathrm{nf}}+\mathrm{W}_{\mathrm{fb}}+\mathrm{W}_{\mathrm{f}} .
$$

Fig. 4 shows the calculated amount of various types of water in the $\mathrm{IH}$ samples of varying $\mathrm{W}_{\mathrm{c}}$ values. The differential scanning calorimetry thermograms for $\mathrm{IH}$ at $\mathrm{W}_{\mathrm{c}}$ $<0 \cdot 21$, do not show any exothermic and/or endothermic peak on the cooling or heating curves. All the sorbed water is bound as non-freezing water. From $\mathrm{W}_{\mathrm{c}} 0 \cdot 31-0 \cdot 51$, IH chains cluster close together and water molecules disperse among the polymer networks. Water molecules very close to the IH chains are affected strongly by the hydrophilic groups on the IH chains and exist as the non-freezing water. Other water molecules within the IH chains interact with the hydrophilic groups and cannot freeze during the cooling process. The water exists as amorphous ice and is in the glassy state and shows a glass transition temperature.

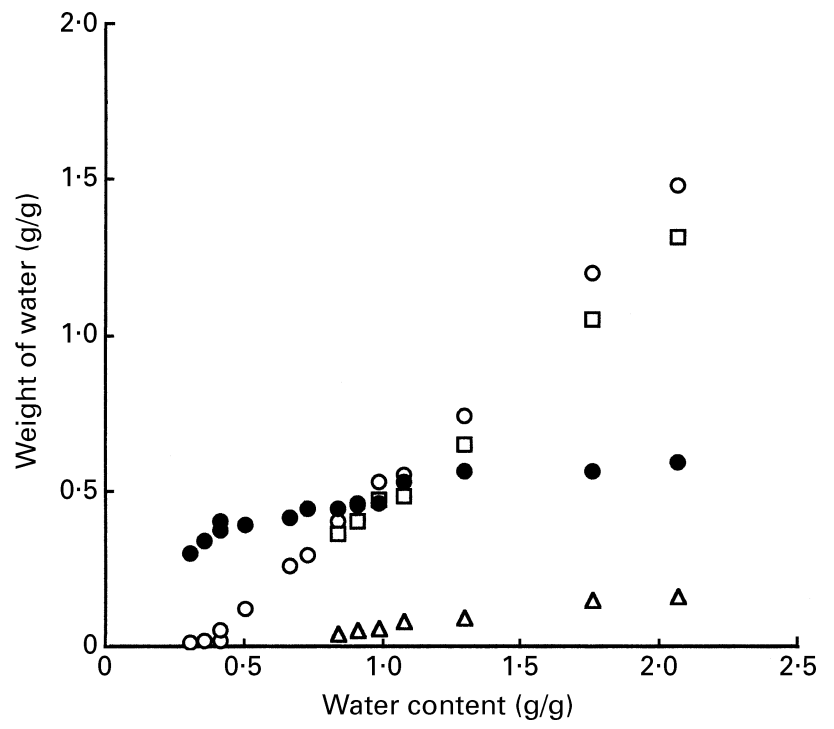

Fig. 4. Distribution of the amounts of various types of water associated with ispaghula husk as a function of water content $\left(\mathrm{W}_{\mathrm{c}}\right)$ within the range $W_{c} 0-2 \cdot 3$. $(O)$, Total water; $(\Delta)$, bound water; $(\square)$, free water; $(\bullet)$, non-freezing water.

This ice in a neighbouring molecular chain will fuse as bound water and shows a melting temperature below $0^{\circ} \mathrm{C}$. The ice with least interaction with $\mathrm{IH}$ chains, which exists apart from polymer chains, will fuse at $0^{\circ} \mathrm{C}$ as free water. Since the melting temperature of ice induced by the cold crystallisation within this water-content region is observed below $0^{\circ} \mathrm{C}$, the water exists as bound water. However, most of the water exists as non-freezing water at these $\mathrm{W}_{\mathrm{c}}$ values.

IH with $\mathrm{W}_{\mathrm{c}}>0.51$ contains another type of water, the existence of which is more clearly demonstrated with increasing $\mathrm{W}_{\mathrm{c}}$. When the $\mathrm{W}_{\mathrm{c}}$ increases up to 0.73 , IH chains are widened partially by water and then water absorbs among $\mathrm{IH}$ chains as non-freezing water, hypercooled water and bound water. In this region, the cold crystallisation is still observed and it is difficult to distinguish bound water from free water. As the $\mathrm{W}_{\mathrm{c}}$ further increases, the molecular distance is further opened and the space that can retain water as hypercooled water disappears. From $\mathrm{W}_{\mathrm{c}} 0 \cdot 84-2 \cdot 1$, the endothermic peak of the heating curve shows a shoulder and it is possible to divide this peak into two parts. The weight of water of the former part is very low and shows a lower melting point. This water can be regarded as bound water. On the other hand, the water belonging to the second part is the dominant water within the IH and its melting point is observed below $0^{\circ} \mathrm{C}$, with the melting point increasing with increasing $\mathrm{W}_{\mathrm{c}}$ up to $7 \cdot 3$. Accordingly, it is difficult to consider this water as free water. The water is a mixture of normal free water showing a melting point at $0^{\circ} \mathrm{C}$ and water weakly interacting with the polymer, which will be regarded as secondary bound water hereafter. The amount of free water increases with increasing $\mathrm{W}_{\mathrm{c}}$, but the secondary bound water does not increase.

Thus, sorbed water in IH with $\mathrm{W}_{\mathrm{c}}<0 \cdot 21$ exists only in a state of non-freezing water. The non-freezing water 
increases with $\mathrm{W}_{\mathrm{c}}$ and then saturates. The saturation value for water binding can be regarded as a $\mathrm{W}_{\mathrm{c}}$ of $2 \cdot 1$. Thus, in the stiff gel that forms on standing $\mathrm{IH}$ in water is in a mainly free and mobile state.

\section{Conclusion}

In summary, therefore, the IH matrix is capable of interacting with water to yield a visco-elastic system that is capable of being preserved throughout its transit through the colon. This situation arises because the solid matrix can interact with water to give a gel fraction and a completely soluble fraction capable of rapid fermentation to yield shortchain fatty acids. The molecular variables of the matrix, gel and soluble fraction are shown in Fig. 5. In turn, these physical and chemical states can initiate a sequence of physical and physiological processes during transit through the colon. These processes are described in Fig. 6 and enable

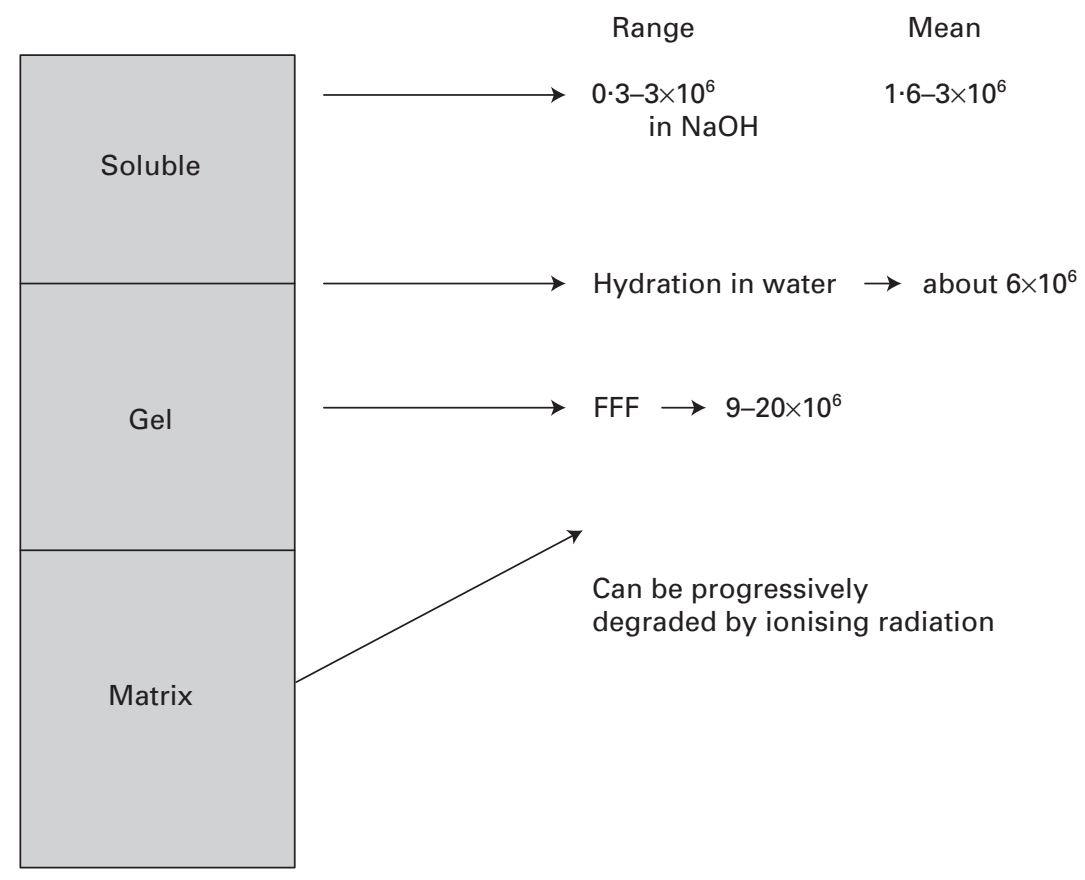

Fig. 5. Molecular weights $(\mathrm{Da})$ of the ispaghula husk solid matrix, the gel and soluble fraction formed by interaction with water. FFF, field-flow fractionation.

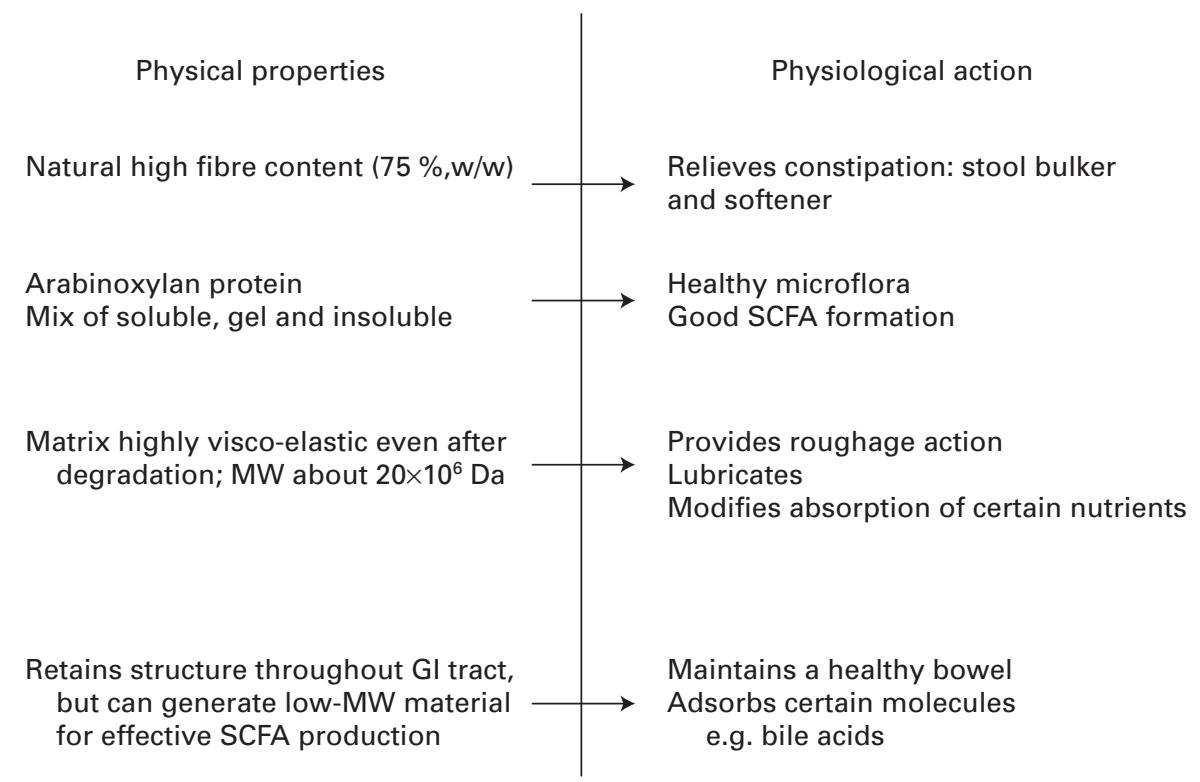

Fig. 6. Relationship between physical properties of ispaghula husk and physiological action in the colon. MW, molecular weight; GI, gastrointestinal; SCFA, short-chain fatty acids. 
the polysaccharide, described as Fybogel (Reckitt Benckiser plc), to be an effective aid to colon health.

\section{References}

Al-Assaf S, Williams PA \& Phillips GO (2002) The molecular characterisation of hyaluronan and hylan. In Hyaluronan 2000. vol. 1, Chemical, Biochemical and Biological Aspects, pp. 55-74. [JF Kennedy, GO Phillips, PA Williams and VC Hascall, editors]. Cambridge: Woodhead Publishing.

Marteau P, Flourie B, Cherbut C, Correze JL, Pellier P, Seyklaz J \& Rabbaud JC (1994) Digestibility and bulking effect of ispaghula husks in healthy humans. Gut 25, 1747-1752.

Milas M, Rinaudo M, Rours R, Al-Assaf S, Phillips GO \& Williams PA (2001) Comparative behaviour of hyaluronan from bacterial and animal sources with cross-linked hyaluronan (Hy lan) in aqueous solution. Biopolymers 59, 191-204.
Takigami S, Takigami M \& Phillips GO (1995) Effect of preparation method on the hydration characteristics of hylan and comparison with another highly cross-linked polysaccharide, gum arabic. Carbohydrate Polymers 26, 11-18.

Viebke C \& Williams PA (2000) Determination of molecular mass distribution of $\mathrm{k}$-carrageenan and xanthan using asymmetrical flow field-flow fractionation. Food Hydrocolloids 14, 265-270.

Wahlund K-G, Gustavsson M, MacRitchie F, Nylander T \& Wannerberger L (1996) Size characterisation of wheat proteins, particularly glutenin, by asymmetrical flow field flow fractionation. Journal of Cereal Science 23, 113-119.

Wittgren B, Wahlund K-G, Derand H \& Wesslen B (1996) Size characterisation of a charged amphiphilic copolymer in solutions of different salts and salt concentrations using flow field-flow fractionation. Langmuir 12, 5999-6005. 